\title{
Key sectors of Optimal Economic Restructuring Constrained by Environmental Protection: A Structured Input-Output Analysis Approach
}

\author{
Alexander Vaninsky \\ Hostos Community College of The City University of New York \\ 500 Grand Concourse, Room B409, Bronx, NY 10451 USA
}

\begin{abstract}
This paper introduces a tool to discover key sectors of a national or regional economy whose shares should be adjusted to offer optimal economic development constrained by environmental protection. The suggested approach uses an appropriately structured input-output model to find the projected gradient of economic development and the projected antigradient of $\mathrm{CO} 2$ emissions. The former is measured as Gross Domestic Product (GDP), the latter, as energy consumption. A linear combination of the two, in a proportion corresponding to the relative importance of GDP and CO2 emissions, determines the direction of optimal economic restructuring. It provides the maximum weighted difference between an increase in the GDP and a decrease in CO2 emissions. The main components of the direction vector show the key sectors. One of the advantages of the suggested approach is its reliance on gross output, final product, and energy consumption only; it does not use the intermediate inputs in the calculations. The United States case study is considered as an example.
\end{abstract}

\section{Indexing terms/Keywords}

Economic restructuring, key sectors, input-output analysis, eco-friendly economic development, GDP maximization, CO2 emissions restriction.

\section{Academic Discipline And Sub-Disciplines}

Economics; Globalization; Social economy; Cooperative societies;

\section{SUBJECT CLASSIFICATION}

Library of Congress Classification HB135-147

\section{TYPE (METHOD/APPROACH)}

Quasi-Experimental

\section{Council for Innovative Research}

Peer Review Research Publishing System

\section{JOURNAL OF SOCIAL SCIENCE RESEARCH}

\author{
Vol.1, No.3




\section{INTRODUCTION}

Economic development and environmental protection have typically been at odds as they pursue different, often mutually exclusive goals. On the one hand, it is crucial to meet the basic needs of people in the developing world where millions live in poverty. On the other hand, environmental degradation, global warming, and climate change, which economic development partially stimulates, will heavily impact our wellbeing. The latest figures state that if the rise in global average temperature exceeds $4^{\circ} \mathrm{C}$ above pre-industrial levels, catastrophic consequences on a global scale may be imminent. Thus, we need to achieve a reasonable sustainable balance between these two objectives.

In this paper, we apply an input-output theory and methodology, Leontief [14], to serve both goals. A conventional inputoutput model relates gross output, intermediate inputs, and final product in a single matrix equation. This equation allows us to estimate the total requirements in the gross output needed to satisfy a desired level of the final product. The total of the components of the final product taken by the sectors of the economy is referred to as the gross domestic product (GDP). The GDP is what the people of a given country can use to satisfy their needs and wants.

The majority of current production processes that drive GDP take a toll on the environment. Among the most far-reaching detrimental byproducts of industry are $\mathrm{CO} 2$ and other gas emissions. As the U.S. Energy Information Agency (EIA) report [23] states, anthropogenic $\mathrm{CO} 2$ emissions stem primarily from energy consumption. Taking this into consideration, we arrive at the problem of decreasing energy use while producing the same or greater GDP.

As was first suggested by W.W. Leontief in publication [13], the input-output methodology may be applied to environmental problems. The idea has been further developed since then; see, for example, publications [20]. The inputoutput models were enhanced to include directly $\mathrm{CO} 2$ and other gas emissions. The energy-related and $\mathrm{CO} 2$-related models have been established in publications $[1,2,3,5,7,9,11,15,20]$, to name a few. Publication [15] provides a review; articles $[4,6,19,29]$ are among the recent on the topic. These publications followed the conventional input-output approach and separated energy or $\mathrm{CO} 2$ emissions flows into three components, related to gross output, intermediate inputs, and final product.

We intend to take a different route here. We consider an economic system as an object producing an undesirable product - CO2 emissions, and adjust an input-output model to this assumption. Since pricing of $\mathrm{CO} 2$ emissions is difficult to calculate, we approximate it by the amount of energy, in dollar value, consumed by economic sectors. Though not all $\mathrm{CO} 2$ emissions are the result of energy consumption, and not every act of energy consumption results in $\mathrm{CO} 2$ emissions, this approximation is used widely in literature. In our case, it allows us to join two input-output models together to optimize the combined outcome.

In this paper, we investigate how the sectoral composition of a national economy should be adjusted so that the same gross output would result in greatest final product and lowest possible $\mathrm{CO} 2$ emissions. More precisely, we intend to uncover the path for economic restructuring that produces the maximum difference between GDP growth and CO2 emissions. We are interested in a timeframe of 5 to 15 years. At the scale of national and regional economies, these timeframes and corresponding changes are small, which allows us to use a gradient vector as the directional vector of optimal change.

We start by transforming a conventional input-output model into a special structured form, whereby the only quantitative indicator is total gross output. All other elements of the model are relative indicators, such as shares of sectoral gross outputs in total or shares of sectoral final product in the corresponding gross output. The suggested approach is based on a mathematical tool developed in Vaninsky [24] that considers GDP as an objective function, with the structured inputoutput model as a set of constraints imposed on its arguments. In that publication, it was shown that the projected gradient of the GDP is a multiple of a function of the structural arguments. It was also found that the components of the projected gradient, corresponding to the sectoral structure of the gross output, are proportional to the deviations of the corresponding final-product components from their average value. This result is crucial for this paper's objective: it enables us to find the gross-output components of the projected gradient without knowledge of the technological matrix. This is the basis behind the computational simplicity of the suggested approach. 
The next step is reorganizing the conventional input-output model. After performing it, the energy consumption takes the place of the final product as an undesirable outcome of production processes that increase $\mathrm{CO} 2$ emissions. At this stage, the construction of the technological matrix may be obviated, since it is not used in the calculations.

We proceed as follows. Given the data on gross output, energy consumption and final product, we calculate two gradient vectors: one for the GDP and one for energy consumption, the latter considered as an approximation of CO2 emissions. Since $\mathrm{CO} 2$ is the undesired byproduct, we take the antigradient, a vector in the opposite direction. In the objective function, the antigradient provides the direction of maximal decrease. A linear combination of the GDP gradient and the energy antigradient with the weight coefficients that correspond to the relative importance of the two factors, points us in the direction of optimal sectoral restructuring. Following this direction yields the maximum difference between an increase in GDP and a decrease in $\mathrm{CO} 2$ emissions. The components of this linear combination, greatest in absolute values, determine the key sectors of the economy. These sectors have the greatest impact, so that economic restructuring should begin with them. The signs and the magnitudes of the projected gradient components show the directions and proportions in which the structural changes should be made. The computational procedure is simple, as shown in the case study of the U.S. economy of 2011 .

The paper is organized as follows. Next section comprises the description of the suggested approach and formulas for computation. It is followed by the section comprising a case study of the U.S. economy.

\section{MATERIALS AND METHODS}

In this section, we find the vector of economic restructuring: changes in the shares of the sectors in the gross output that provide maximum possible increase in the GDP, while exerting the lowest toll possible on the environment. To achieve this goal, we find the gradient of the GDP and the antigradient of CO2 emissions, and obtain their linear combination with weight coefficients that reflect their relative importance. The largest and smallest components of this linear combination yield the key sectors that should be expanded or contracted in the first place.

We use the input-output model, that is a matrix equation relating vectors of gross output $\mathrm{X}$, final product $\mathrm{Y}$, and a technological matrix $A$ :

$$
X=A X+Y \text {. }
$$

Matrix A defines the relationships among the sectors of an economic system. Following Ghosh [10], we transform model (1) to a structured form. To do that, we divide each row of the matrix equation (1) by $\mathrm{Xi}$, the gross output of $\mathrm{i}$-sector, correspondingly. We get

$$
1=\sum_{j=1}^{n} C_{i j}+U_{i}, i=1, \ldots, n
$$

where $C_{i j}=\left(A_{i j} X_{j}\right) / X_{i}$ is a share of gross output of $\mathrm{i}$-sector obtained from the $\mathrm{j}$-sector for technological use, $U_{i}=Y_{i} / X_{i}$ is a share of $i$-final product in $i$-gross output, and $\mathrm{n}$ is the number of sectors in the economy. Each equation in formula (2) corresponds to a particular sector. The sectors are related through variables $D_{i}$, the shares of i-gross output in total:

$$
D_{i}=X_{i} / X
$$

where $X$ is total gross output. As follows from the definition,

$$
\sum_{i=1}^{n} D_{i}=1
$$

An input-output model, given by equations (2) - (4), is referred to below as a structured input-output model.

In this paper, we follow [24] and append the structured input-output model (2) - (4) with an objective function. The model becomes a set of restrictions imposed on the arguments of the objective function. We use two objective functions in this paper: GDP and $\mathrm{CO} 2$ emissions, both expressed as functions of the model variables. The former objective function is subject to maximization, the latter, to minimization.

Consider the GDP-objective function first. The GDP is a sum of the components of vector $Y$ in equation (1). It was shown in [27] that

$$
Y=\sum_{i=1}^{n} Y_{i}=\sum_{i=1}^{n} X_{i} U_{i}=\sum_{i=1}^{n}\left(X D_{i}\right) U_{i}=X \sum_{i=1}^{n} D_{i} U_{i}
$$

where $\mathrm{Y}$ - is GDP equal to the sum of the components of vector $Y$. The components of gradient $\nabla Y$ of the objective function $Y$ are as follows

$$
\frac{\partial Y}{\partial X}=\sum_{i=1}^{n} D_{i} U_{i}, \quad \frac{\partial Y}{\partial D_{i}}=X U_{i}, \quad \frac{\partial Y}{\partial U_{i}}=X D_{i}, \quad \frac{\partial Y}{\partial C_{i j}}=0 .
$$


It may be noted that the gradient components corresponding to the variables Cij are equal to zero, because these variables do not appear in the formula of function (5) explicitly. The gradient provides the direction and the magnitude of maximum increase in the function value per unit of distance.

Since the arguments of the objective function (5) are interconnected by the equations of the structured input-output model (2) - (4), we use the projected gradient. It is known that a projection of a gradient of a function on a surface is the gradient of the restriction of the function to this surface, see [16] for detail. Keeping this observation in mind, we project gradient (5) on the hyperplane defined by equations (2) and (4). Using projected gradient in this type of problems may be traced to empirical formulas proposed in Meerovich [18] and Vaninsky and Meerovich [28], and mathematical theory developed in $[25,26]$. A brief review may be found in [16].

As shown in [27], the projected gradient of the objective function (5) is

$$
\begin{aligned}
\operatorname{Proj}_{H} \nabla Y=X( & U_{1}-\bar{U}, U_{2}-\bar{U}, \ldots, U_{n}-\bar{U}, \\
& -\frac{D_{1}}{n+1}, \ldots,-\frac{D_{1}}{n+1},-\frac{D_{2}}{n+1}, \ldots-\frac{D_{2}}{n+1}, \ldots,-\frac{D_{n}}{n+1}, \ldots-\frac{D_{n}}{n+1}, \\
& \frac{n D_{1}}{n+1}, \ldots, \frac{n D_{n}}{n+1}, \\
& \quad \text { ) }
\end{aligned}
$$

Where $\nabla Y$ is a gradient of function $Y, H$ is a hyperplane defined by equations (2) and (4), $\operatorname{Proj}_{H} \nabla Y$ is a projection of $\nabla Y$ on $H$, and $\bar{U}=\left(U_{1}+\ldots+U_{n}\right) / n$ stands for the average value of variables $U_{i}$. The first $n$ components of the projected gradient correspond to variables $D_{i}$, the shares of $i$-gross output in total; next $n^{2}$ components - to the variables $C_{i j}$, elements of the technological matrix $A$; the following $n$ components - to the variables $U_{i}$, shares of $i$-final product in the $i$-sector gross output, and the last component is zero. The latter corresponds to the total gross output $X$; its zero value means that in our case the structural changes do not affect total gross output.

Since this paper's objective is economic restructuring, that is the change in the sectoral composition of the economy, we focus on the first $n$ components of the projected gradient vector only. From formula (7), it follows that

$$
\frac{\partial Y}{\partial D_{i}}=X\left(U_{i}-\bar{U}\right)
$$

This means that in the direction of the projected gradient, the impact of structural variable $D_{i}$ on the final product is proportional to the deviation of the corresponding share of the $i$-final product in the $i$-gross output from the average value. Since only relative magnitudes and the signs of structural change are important for the objectives of this paper, we can drop factor $X$, the total gross output, in formula (8). By doing so, we get the components of the projected gradient in terms of the total gross output $X$. It should be noted that the technological matrix $\boldsymbol{A}$ - the most methodologically and computationally complex element of the input-output models - does not appear in formula (8). This fact is an important advantage of the approach we suggest and the cause of its computational simplicity.

To combine the production and emission processes in the input-output framework, we consider $\mathrm{CO} 2$ emissions as an undesirable byproduct of the economy, [8]. Furthermore, we use energy consumption for the approximation of $\mathrm{CO} 2$ emissions. This approximation is widely used in literature though it is known that: (1) only approximately $80 \%$ of $\mathrm{CO} 2$ emissions are due to energy consumption (in the United States it is $87 \%$ ), (2) some energy consuming processes do not result in $\mathrm{CO} 2$ emissions, and (3) energy consumption expressed in monetary units has an additional error due to the difference in taxes and subsidies. The total energy requirements by sectors may be found based on energy intensities, as shown in [5]. In this paper we use an approximation of the vector of direct energy consumption E. We use the KLEMS (Capital, Labor, Energy, Materials, and Services) part of the input-output table and adjust the Energy component for the amount of energy transferred to or obtained from other sectors:

$$
E_{A d j}=E-E^{\prime}+E^{\prime \prime}
$$

where $\boldsymbol{E}^{\prime}$ and $\boldsymbol{E}^{\prime \prime}$ are the vectors of energy transferred to or from the sectors, respectively. Our objective is to keep the balance of gross output rather than the energy balance.

To find the amounts of energy transferred to or from a given sector, we start with the matrix of intermediate input $\boldsymbol{M}$ :

$$
\boldsymbol{M}=\boldsymbol{A} \cdot \operatorname{diag}(\boldsymbol{X})
$$

Where $\boldsymbol{A}$ is the technological matrix, and $\operatorname{diag}(\boldsymbol{X})$ stands for a diagonal matrix with the values of sectoral gross output $X_{i}$ on the diagonal. Using matrix $\boldsymbol{M}$, we separated the energy component, in dollar amounts, from the intermediate input, resulting in matrix $\boldsymbol{M}_{\boldsymbol{E}}$. The elements matrix $\boldsymbol{M}_{\boldsymbol{E}}$ were calculated as the gross-output proportions of sectoral energy consumptions:

$\left(\boldsymbol{M}_{\boldsymbol{E}}\right)_{i j}=E_{j} \cdot(\boldsymbol{M})_{i j} / X_{j}=E_{j} \cdot(\boldsymbol{A})_{i j}$.

The last term of formula (11) suggests a shorter way of calculating matrix ME as

$$
\boldsymbol{M}_{\boldsymbol{E}}=\boldsymbol{A} \cdot \operatorname{diag}(\boldsymbol{E}) \text {, }
$$

74 | $P$ a g e 
where $\operatorname{diag}(\boldsymbol{E})$ stands for a diagonal matrix with the values of sectoral energy consumption $E_{i}$ on the diagonal.

The amount of energy transferred from sector $i$ to the other sectors equals

$$
E_{i}^{\prime}=\left(M_{E}\right) *_{i}
$$

the amount of energy obtained by sector $i$ from the other sectors equals

$E_{i=}^{\prime \prime}\left(M_{E}\right)_{i^{*}}$,

where $\left(\boldsymbol{M}_{E}\right)_{\mathrm{ij}}$ stands for the element of matrix $\boldsymbol{M}_{\boldsymbol{E}}$ located at the intersection of $i$-th row and $j$-th column, $\left(\boldsymbol{M}_{E}\right)_{*_{\mathrm{i}}}$ and $\left(\boldsymbol{M}_{E}\right)_{\mathrm{i}^{*}}$, for the sum of the elements of the $i$-th column and $i$-th row, correspondingly, and $E_{i}^{\prime}$ and $E^{\prime \prime}{ }_{i}$ are the components of vectors $E^{\prime}$ and $E^{\prime \prime}$, respectively.

By doing so, we obtain an input-output model relating gross output and total energy consumption: $X=A_{E} X+E_{A d j}$

where $\boldsymbol{A}_{E}$ is a technological matrix corresponding to the non-energy intersectoral transfers. This matrix may be obtained from the Use and Make tables and the "Composition of Gross Output by Industry" table [21], see, for example, [5,12]. For the objectives of this paper, this matrix is not needed however.

Following [27] as above, we get

$$
\frac{\partial E_{A d j}}{\partial D_{i}}=X\left(U_{E i}-\bar{U}_{E}\right)
$$

where $U_{E i}$ is a share of the total energy consumption, in monetary units, in the gross output of $i$-sector, and $\bar{U}_{E}$ is the average value of $U_{E i}$ 's. Since $\mathrm{CO} 2$ emissions are an undesirable outcome, we use the antigradient in the calculations below, the vector $-\operatorname{Proj}_{H} \nabla E$, and the inverse of its components given by formula (16). The antigradient provides direction and magnitude of the maximum decrease in the total energy consumption per unit of distance. Similarly to what was said above, we drop factor $\mathrm{X}$ in our calculations.

The economic restructuring that follows the direction of

$$
d=\operatorname{Pr}_{0 j} \nabla Y-\operatorname{Pr}_{H} \nabla j_{H} \nabla E
$$

provides the maximum difference between an increase in the GDP and decrease in $\mathrm{CO} 2$ emissions, the latter measured as total energy consumption.

\section{RESULTS AND DISCUSSION}

We apply the aforementioned approach to the 2011 data of the United States' economy. The website of the U.S. Bureau of Economic Analysis, www.bea.gov, offers the necessary statistical information. The data are presented in Table 1, together with calculations. The names of some sectors were shortened for readability. Gross output and energy data were collected from the table "Composition of Gross Output by Industry" [21]. The gross output is shown in column 2. The final product was calculated by using the Leontief inverse matrix $\mathrm{T}$, referred to in the "Industry-by-Industry Total Requirements Table" [22]. With regard to formula (1),

$$
T=(I-A)^{-1} \text {, }
$$

where $I$ stands for the identity matrix. Based on this formula, we calculated the final product as $Y=T^{1} X$

The final product is shown in column 3 . Its value for the mining sector is negative. This observation does not prevent using formula (8) in the calculations, but requires a more detailed

analysis beyond the scope of this paper. The sectoral energy consumptions were calculated by using formula (12), where the technological matrix $A$ equals

$$
\boldsymbol{A}=\boldsymbol{I}-\boldsymbol{T}^{1} \text {. }
$$

The values of sectoral energy consumption, in dollar amounts, adjusted for the intersectoral energy transfer are listed in column 4; they were used as approximations for $\mathrm{CO} 2$ emissions.

The calculations began with finding the shares of the final product and energy in the gross output, columns 5 and 7 , respectively. Corresponding average values are shown in the last row. Columns 6 and 8 show the deviations and inverses of the deviations from the corresponding average values. As follows from formulas (8) and (16), they are the components of the gradient of the final product and the antigradient of adjusted energy consumption, respectively, expressed in terms of gross output $X$.

Using formula (17), we received the direction of optimal restructuring in column 9. Values shown in this column represent the proportions and the signs of change in the shares of sectors in the gross output that provide the maximum difference between the increase in the GDP and CO2 emissions. Note that the sums of the changes in columns 6, 8, and 9 are zero, because the shares of all sectors sum up to one.

As follows from the results, the shares of the following key sectors should be changed first, according to the following directions and proportions: education (0.4678), retail trade (0.4477), and government (0.3906); mining (-0.8916), 75 | P a g e 
agriculture (-0.4102), and services (-0.3792). Any prospective changes should add up to zero. The proposed change to the mining sector deserves special consideration because of the negative value of the final product that underlies it. The obtained results could have been made more exact if the $\mathrm{CO} 2$ input-output tables were available.

In the light of the obtained results the rivalry of the two objectives - economic development and environment protection may be reconsidered. The gradient of the GDP and antigradient of energy consumptions may be viewed as two vectors in plane, with an angle between them being an indicator of their relative position. The angle measure of $0^{\circ}$ corresponds to the coincidence of the two objectives, $90^{\circ}$, to their independence, and $180^{\circ}$, to rivalry. A formula for the cosine of an angle between two vectors $\boldsymbol{u}$ and $\boldsymbol{v}$ is this:

$$
\cos \theta=\frac{\boldsymbol{u} \cdot \boldsymbol{v}}{|\boldsymbol{u}| \cdot|\boldsymbol{v}|}
$$

where $\boldsymbol{u} \cdot \boldsymbol{v}$ is the dot-product of the vectors - the sum of the component-wise products, and $|\boldsymbol{u}|$ and $|\boldsymbol{v}|$ are their lengths, respectively:

$$
\begin{aligned}
& \boldsymbol{u} \cdot \boldsymbol{v}=u_{1} \cdot v_{1}+u_{2} \cdot v_{2}+\ldots+u_{n} \cdot v_{n}, \\
& |\boldsymbol{u}|=\sqrt{u_{1}{ }^{2}+u_{2}{ }^{2}+\ldots+u_{n}{ }^{2}},|v|=\sqrt{v_{1}{ }^{2}+v_{2}{ }^{2}+\ldots+v_{n}{ }^{2}}
\end{aligned}
$$

Using these formulas for the gradient of the GDP and antigradient of energy consumption - columns 6 and 8 of the table 1 , respectively - we got $\cos \theta=0.4734$, so that $\theta=61.7^{\circ}$. Based on the value of the angle, we could conclude that for the U.S. economy of 2011 the two objectives were not rivals.

This observation sheds the light on the possible strategies of economic restructuring expanding the one presented by formula (17) and column 9 of the table 1. The first way is to follow the GDP-gradient with a partial decrease in energy consumption. The second way is to follow the energy-consumption antigradient at the expense of the GDP. The third is to pursue both goals simultaneously, partially satisfying both objectives. One of the versions of this strategy is economic restructuring directed by the bisector of the GDP - gradient and energy-consumption antigradient. The choice of the

\begin{tabular}{|c|c|c|c|c|c|c|c|c|}
\hline Sectors $^{1}$ & $\begin{array}{l}\text { Gross } \\
\text { Output, } \\
\text { BIn \$ }\end{array}$ & $\begin{array}{l}\text { Final } \\
\text { Product, } \\
\text { Bln } \$^{2}\end{array}$ & $\begin{array}{l}\text { Energy, } \\
\text { Bln } \$^{3}\end{array}$ & $\begin{array}{l}\text { Final } \\
\text { Product, } \\
\text { Share of } \\
\text { Gross } \\
\text { Output, } \\
\text { r.u. }\end{array}$ & $\begin{array}{l}\text { Final } \\
\text { Product, } \\
\text { Deviation } \\
\text { from } \\
\text { average, } \\
\text { r.u. }{ }^{4} \\
\text { GDP } \\
\text { gradient }^{5}\end{array}$ & $\begin{array}{l}\text { Energy, } \\
\text { Share } \\
\text { of } \\
\text { Gross } \\
\text { Output, } \\
\text { r.u. }\end{array}$ & $\begin{array}{l}\text { Energy, } \\
\text { Deviation } \\
\text { from } \\
\text { average, } \\
\text { inverses, } \\
\text { r.u. }^{4} \\
\text { Energy }^{\text {antigradient }}{ }^{5}\end{array}$ & $\begin{array}{l}\text { Sum of the } \\
\text { GDP gradient } \\
\text { and Energy } \\
\text { antigradient }^{5}\end{array}$ \\
\hline$(1)$ & (2) & (3) & (4) & $(5)$ & (6) & $(7)$ & $(8)$ & (9) \\
\hline Calculations & & & & $(3) /(2)$ & (5)-Avrg & $(4) /(2)$ & (7)-Avrg & $(6)+(8)$ \\
\hline Agriculture & 420.0 & 61.7 & 25.7 & 0.1468 & $3 \quad-0.3784$ & 0.0613 & -0.0318 & -0.4102 \\
\hline Mining & 532.5 & -184.5 & 26.3 & -0.3465 & -0.8717 & 0.0494 & -0.0198 & -0.8916 \\
\hline Utilities & 377.1 & 201.7 & 20.3 & 0.5349 & 0.0096 & 0.0540 & -0.0244 & -0.0148 \\
\hline Construction & 981.7 & 770.8 & 21.5 & 0.7852 & 0.2599 & 0.0219 & 0.0077 & 0.2676 \\
\hline $\begin{array}{l}\text { Manufacturing } \\
\text { Wholesale }\end{array}$ & 5419.5 & 1881.7 & 129.1 & 0.3472 & -0.1780 & 0.0238 & 0.0057 & -0.1723 \\
\hline trade & 1295.7 & 777.6 & 19.0 & 0.6002 & 0.0749 & 0.0147 & 0.0149 & 0.0898 \\
\hline Retail trade & 1354.8 & 1290.4 & 12.3 & 0.9525 & 0.4272 & 0.0091 & 0.0204 & 0.4477 \\
\hline Transportation & 845.7 & 357.8 & 94.3 & 0.4231 & -0.1022 & 0.1116 & -0.0820 & -0.1842 \\
\hline Information & 1258.3 & 643.1 & 12.8 & 0.5110 & -0.0142 & 0.0102 & 0.0193 & 0.0051 \\
\hline Finance & 4901.6 & 2653.6 & 48.1 & 0.5414 & 0.0161 & 0.0098 & 0.0197 & 0.0359 \\
\hline Services & 2769.6 & 394.2 & 71.4 & 0.1423 & -0.3829 & 0.0258 & 0.0038 & -0.3792 \\
\hline Education & 2121.2 & 2058.4 & 14.5 & 0.9704 & 0.4451 & 0.0069 & 0.0227 & 0.4678 \\
\hline Art & 1051.0 & 771.4 & 19.8 & 0.7339 & 0.2087 & 0.0188 & 0.0107 & 0.2194 \\
\hline Other & 572.1 & 363.5 & 6.4 & 0.6353 & 0.1101 & 0.0112 & 0.0184 & 0.1284 \\
\hline Government & 3354.1 & 3022.3 & 49.6 & 0.9011 & 0.3758 & 0.0148 & 0.0148 & 0.3906 \\
\hline
\end{tabular}
strategy depends on the goals of the economic development and the value assigned to the environment protection.

Table 1. Key sectors of the U.S. economy, 2011

76 | P a g e 

Average
0.5253
$0.0000 \quad 0.0295$
0.0000
0.0000

Notes

1 Agriculture includes agriculture, forestry, fishing, and hunting sectors. Transportation includes transportation and warehousing sectors. Finance includes finance, insurance, real estate, rental, and leasing sectors. Services include professional and business services. Education includes educational services, health care, and social assistance. Arts include arts, entertainment, recreation, accommodation, and food services sectors. Other services exclude government services.

${ }^{2}$ Calculated as $\boldsymbol{Y}=\boldsymbol{T}^{\mathbf{1}} \cdot \boldsymbol{X}$

${ }_{4}^{3}$ Adjusted for intersectoral energy transfer.

4 r.u. stands for relative units.

${ }^{5}$ Gradient and antigradient in terms of total gross output $X$.

${ }^{6}$ Energy is used as an approximation for the $\mathrm{CO} 2$ emissions.

\section{CONCLUSIONS}

The paper suggests an approach to finding the optimal economic restructuring of a national or regional economy adjusted for environmental protection. The proposed direction of economic restructuring provides the maximum difference between the growth of GDP and CO2 emissions, the last measured as energy consumption. A combination of two structured inputoutput models allowed us to rank the sectors of the economy according to the suggested criteria, thus pointing out the key sectors. A case study of the United States' economy of 2011 revealed that the best production-emissions results would be obtained if the shares of the education, retail trade, and government sectors were increased, accompanied by the corresponding decrease in the shares of the mining, agriculture, and services sectors.

\section{REFERENCES}

[1] Ayres, R. and Kneese, A. 1969. Production, consumption and externalities. American Economic Review, 59(3), 282297.

[2] Bullard, C and Herendeen, R. 1975. The energy costs of goods and services. Energy Policy, 1(4), $268-277$.

[3] Bullard, C., Penner, P. and Pilati, D. 1978. Energy anslysis handbook. Resources and Energy, 1, 267-313.

[4] Butnar, I. and Llop, M. 2011. Structural decomposition analysis and input-output subsystems: Changes in CO2 emissions of spanish service sectors (2000-2005). Ecological Economics, 70(11), 2012-2019.

[5] Casler, S. and Wilbur, S. 1984. Energy input-output analysis: A simple guide. Resources and Energy, 6(2),187-201.

[6] Cellura, M., Di Gangi, A., Longo, S. and Orioli, A. 2013. An Italian input-output model for the assessment of energy and environmental benefits arising from retrofit actions of buildings. Energy and Buildings, 62, 97-106.

[7] Cumberland, J. 1966. A regional inter-industry model for analysis of development objectives. Papers of the regional science association , 17, 65-94.

[8] Färe, R., Grosskopf, S., Lovell, C. and Pasurka, C. 1989. Multilateral productivity comparisons when some outputs are undesirable: A nonparametric approach. The Review of Economics and Statistics 71: 90-98.

[9] Flaschel, P. 1982. Input-output technology assumptions and the energy requirements of commodities. Resources and Energy, 4, 359-389.

[10] Ghosh, A. 1964. Experiments with Input - Output Models. Cambridge: Cambridge University Press.

[11] Griffin, J. 1976. Energy input-output modeling, Palo Alto, California: Electric power research institute.

[12] Guo, J, Lawson, A. and Planting, M. 2002.. From Make-Use to Symmetric I-O Tables: An Assessment of Alternative Technology Assumptions, U.S. Department of Commerce, Bureau of Economic Analysis, Working Paper WP2002-03. Available at www.bea.gov.

[13] Leontief, W. 1970. Environmental repercussions and the economic structure. An input-output approach. Review of Economics and Statistics, 52(3), 262-271.

[14] Leontief, W. 1986. Input - Output Economics. 2nd. Ed. Oxford University Press, New York.

[15] Lin, G. 1998. Energy development and environmental constraints in China.Energy Policy, 26(2),119-128(10).

[16] Maital, S. and Vaninsky, A. 2000. Productivity Paradoxes and their Resolution. Journal of Productivity Analysis, 14(3), 191-207.

[17] Mayer, H. and Flachmann, C. 2011. Extended Input-Output Model for Energy and Greenhouse Gases. Final Report. Federal Statistical Office Germany, Environmental-Economic Accounting.

77 I $P$ a g e 
[18] Meerovich, V. Turnover of Financial Funds and Efficiency of Production. (Oborot Sredstv i Effektivnost' Proizvodstva), Finance, Moscow. (In Russian.)

[19] Su, B. and Ang, B. 2013. Input-output analysis of CO2 emissions embodied in trade: Competitive versus noncompetitive imports. Energy Policy, 56, 83-87.

[20] Suh, S. (Ed.) 2009. Handbook of Input-Output Economics in Industrial Ecology, Dordrecht/Heidelberg/NewYork: Springer, 2009.

[21] U.S. Bureau of Economic Analysis, Composition of Gross Output by Industry, www.bea.gov/iTable/iTable.cfm?ReqID=5\&step=1\#reqid=5\&step=4\&isuri=1\&402=25\&403=1 (accessed June 11, 2013).

[22] U.S. Bureau of Economic Analysis, Industry-by-Industry Total Requirements after Redefinitions, www.bea.gov/iTable/iTable.cfm?ReqID=5\&step=1\#reqid=5\&step=102\&isuri=1\&405=Sec\&406=10\&402=15\&403=2\&4 04=7 (accessed June 11, 2013.

[23] U.S. Energy Information Administration, International Energy Outlook 2011. http://www.eia.gov/forecasts/ieo/emissions.cfm (accessed June, 11, 2013)

[24] Vaninsky, A. 2006. Computational Method of Finding Optimal Structural Change in Economic Systems: An Inputoutput Projected-gradient Approach. Journal of Interdisciplinary Mathematics, 9(1), 61 - 76.

[25] Vaninsky, A. 1987. Factorial Analysis of Economic Activity. (Factornyi Analiz Khozyaistbennoi Deyatel'nosti), Finance and Statistics, Moscow. (In Russian)

[26] Vaninsky, A. 1984. Generalization of the integral method of economic analysis to interconnected and derived factors. Automation and Remote Control, $44: 8: 2,1074$ - 1083.

[27] Vaninsky, A. 2009. Structural Change Optimization in Input - Output Models. Journal of Interdisciplinary Mathematics, $12(6), 839-861$

[28] Vaninsky, A. and Meerovich, V. Problems of the methodology of analysis of the impact of structural change on the indicators of production efficiency. (Voprosy metodologii analiza vliyaniya strukturnykh sdvigov na pokazateli effectivnosti proizvodstva.) Proceedings of the National Scientific Conference "Economic Leverages of the Efficiency of Using Material, Labor, Financial, and Natural Resourses", 2, 105 - 107, Central Economic - Mathematical Institute, Moscow, 1978. (In Russian)

[29] Wang, Y. and Liang, S. 2013. Carbon dioxide mitigation target of China in 2020 and key economic sectors. Energy Policy, 58, 90-96.

\section{Author' biography with Photo}

Dr. Alexander Vaninsky is currently a Professor of Mathematics at Hostos Community College of the City University of New York. He received his master's degree in electrical engineering from the Moscow Power Engineering Insitute, in mathematics - from Moscow State University, and Ph.D. and D. Sc. Degrees in mathematical economics - from Moscow Finance University. Author and co-author of five monographs and over 30 articles. Recipient of different grants and awards; among them - Stephen J. Shaw Award for Most Outstanding Paper (Irwin Publishing, USA) and Award for Outstanding Paper in Channels, Retail \& Services (Southern Marketing Association of the USA). Teaches courses in Mathematics and Economics. Served as a Member of the Board of Directors and an advisor to government and private companies. Included in the Who's Who in America and Who's Who in the World. His current research focuses on the development and applications of new methods of environmental analysis including structured input - output models and data envelopment analysis with a perfect object.

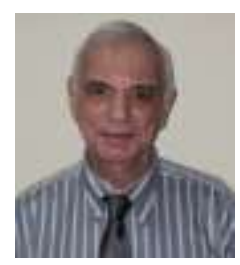

78 | P a g e 